\title{
Synthesis and photoluminescence properties of novel polyarylates bearing pendent naphthylamine chromophores
}

\author{
Guey-Sheng Liou ${ }^{\mathrm{a}, *}$, Shih-Ming Lin ${ }^{\mathrm{b}}$, Hung-Ju Yen ${ }^{\mathrm{a}}$ \\ ${ }^{a}$ Functional Polymeric Materials Laboratory, Institute of Polymer Science and Engineering, National Taiwan University, 1, Roosevelt Road, \\ 4th Sec., Taipei 10617, Taiwan \\ ${ }^{\mathrm{b}}$ Functional Polymeric Materials Research Laboratory, Department of Applied Chemistry, National Chi Nan University, 1, University Road, Puli, Nantou Hsien \\ 54561, Taiwan
}

\section{A R T I C L E I N F O}

\section{Article history:}

Received 26 December 2007

Received in revised form 6 May 2008

Accepted 30 May 2008

Available online 8 June 2008

\section{Keywords:}

Triarylamine

Polyarylates

Photoluminesence

Solvatochromism

Naphthylamine

\begin{abstract}
A B S T R A C T
A new series of blue photoluminescent aromatic polyesters (polyarylates) were synthesized from 1-[N,N-di(4-carboxyphenyl)amino]naphthalene with various bisphenols by the diphenylchlorophosphate (DPCP) activated direct polycondensation in a medium of pyridine and lithium chloride. The synthesis, basic characterizations, photoluminescence and electrochemical properties of this series of novel polyarylates bearing pendent naphthylamine chromophores were investigated. All polymers not only had good solubility in many polar aprotic solvents and excellent thin-film-forming ability, but also exhibited high $T_{\mathrm{g}}$ values, good thermal stability and lower highest occupied molecular orbital (HOMO) level. Thus, these naphthylamine-containing polyarylates may be widely applied in P-LED as hole-transporting layer and blue light-emitting materials due to their proper HOMO level, excellent thermal stability and fluorescence quantum efficiency.
\end{abstract}

(c) 2008 Elsevier Ltd. All rights reserved.

\section{Introduction}

It is well known that wholly aromatic polyesters (polyarylates) possess high thermal stability and excellent mechanical properties with high visible-light transparency [1]. The polyiso/terephthalate of bisphenol A (U-polymer) is an example of commercially available polyarylate that has a glass transition temperature $\left(T_{\mathrm{g}}\right)$ of $195^{\circ} \mathrm{C}$ and is melt processable. Recently, modulation of their photophysical and electrical properties by means of a simple condensation synthetic method may be an impressive challenge in terms of new development of polymeric light-emitting diodes (PLEDs) materials.

Polymeric light-emitting diodes (PLEDs) are readily available in all the three primary colors. However, blue light-emitting materials remains an area of intense research activity to compete with the GaN-based inorganic LEDs. Furthermore, in full-color displays, the polymer with

\footnotetext{
* Corresponding author.

E-mail address: gsliou@ntu.edu.tw (G.-S. Liou).
}

a large energy band gap that can efficiently emit blue light and also serve as the energy-transfer donor in the presence of low energy fluorophores is highly desirable.

In order to obtain high- $T_{\mathrm{g}}$ 's hole-transporting layer and blue light-emitting materials, many investigations have been done, such as triarylamine (TPA) and carbazole $(\mathrm{Cz})$ based polymers used in multilayer organic electroluminescence (EL) devices [2-6], poly(1,4-phenylenevinylene)s (PPV) and polyfluorenes (PF) based polymers containing TPA or $\mathrm{Cz}$ in the emissive $\pi$-conjugated core/main chains [7-11] or grafting them as side chains in a polymer [1214] or attaching them onto the polymer chain-ends or the outer surface of dendritic wedges $[15,16]$. Recently, we also have reported the synthesis of organosoluble aromatic poly(amine-hydrazide)s and poly(amine-1,3, 4-oxadiazole)s bearing naphthylamine chromophore in the main chain based on $1-[N, N-d i(4-$ carboxyphenyl)amino]naphthalene [17] with high quantum yield of $34 \%$ and $32 \%$ in $N$-methyl-2-pyrrolidone (NMP), respectively. And polyarylates bearing triphenylamine groups in the main chain based on $4,4^{\prime}$-dicarboxytriphenylamine 
[18] with high quantum yield of $32.6 \%$ in tetrahydrofuran (THF). Because of the incorporation of bulky naphthylamine chromophores or triphenylamine groups along the polymer backbone, all the polymers were amorphous with high $T_{\mathrm{g}}$ and enhanced thermal stability, showed good solubility in many polar aprotic solvents and good film-forming capability.

Here a newly series of blue photoluminescence aromatic polyesters (polyarylates) were synthesized from 1-[N, $\mathrm{N}$ di(4-carboxyphenyl)amino]naphthalene with various bisphenols by the diphenylchlorophosphate (DPCP) activated direct polycondensation in a medium of pyridine and lithium chloride. The 1-naphthylamine moieties are bulky and aromatic ones, so it is good for preserving the thermal stability of the polymers. When the 1-naphthylamine moieties are incorporated into the polymer backbone to form a triarylamine structure, it would generally disrupt the coplanarity of the aromatic unit to decrease stacking efficiency, then reduce interchain interactions and the between chains space will be improved. After that the polymer solubility will elevate at the same time. As for the ester group linkage, a kind of nonconjugated spacers, we expect it will conduce toward large band gap for blue light emission.

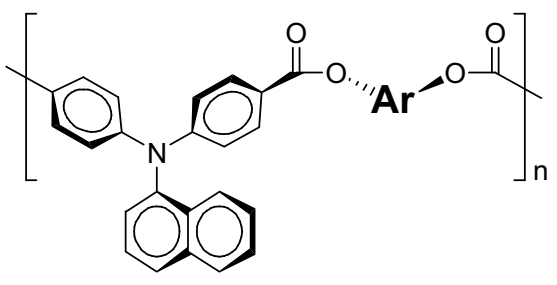

In addition, the prepared naphthylamine-containing polyarylates may find application in organic photoluminescent element because naphthylamine derivatives and polymers are reputed to be light-emitting materials and the ester group linkage will effectively prevent the electrons to delocalize along the polymer chains, so that the energy will not be quenched. The general properties such as solubility and thermal properties are reported, the electrochemical and photoluminescent properties of these polymers are also described herein and are compared with those of structurally related ones from 4,4'-dicarboxytriphenylamine ( $\left.\mathbf{I}^{\prime}\right)$ [18].

\section{Experimental}

\subsection{Materials}

The naphthylamine-based aromatic dicarboxylic acid, 1[N,N-di(4-carboxyphenyl)amino]naphthalene (2) (mp: $315-317^{\circ} \mathrm{C}$ by differential scanning calorimetry, DSC), was successfully synthesized by the sodium hydride-mediated condensation of 1-aminonaphthalene with 4-fluorobenzonitrile, followed by the alkaline hydrolysis of the intermediate dinitrile compound (1) (mp: $167-169^{\circ} \mathrm{C}$ by DSC) according to a previously reported procedure [17]. 4,4'Dicarboxytriphenylamine (mp: $313-315^{\circ} \mathrm{C}$ by DSC) was synthesized by the condensation of aniline with 4-fluorobenzonitrile in the presence of sodium hydride, followed by the alkaline hydrolysis of the intermediate dinitrile com- pound according to a previously reported procedure [19]. The bisphenol monomers that include 4,4'-dihydroxydiphenyl ether (3a) (TCI), 4,4'-isopropylidenediphenol (3b) (ACROS), 2,2-bis(4-hydroxyphenyl)-hexafluoropropane (3c) (TCI), phenolphthalein (3d) (Aldrich), and 9,9-bis(4hydroxyphenyl)fluorine ( $3 e$ ) (TCI) were purified by recrystallization from solvents. Commercially obtained anhydrous lithium chloride $(\mathrm{LiCl})$ was dried under vacuum at $150^{\circ} \mathrm{C}$ for $10 \mathrm{~h}$. Tetrabutylammonium perchlorate (TBAP) (ACROS) was recrystallized twice from ethyl acetate and then dried in vacuo prior to use. All other reagents were used as received from commercial sources.

\subsection{Polymer synthesis}

\subsubsection{Preparation of the polyarylates via the direct polycondensation}

The synthesis of polyarylate Ib was used as an example to illustrate the general synthetic route used to produce the polyarylates. A solution of diphenylchlorophosphate (DPCP) $(0.69 \mathrm{~g}), \mathrm{LiCl}(0.09 \mathrm{~g})$, and pyridine $(2.0 \mathrm{~mL})$ was stirred at room temperature for $30 \mathrm{~min}$ and then added dropwise for $20 \mathrm{~min}$ to a hot solution (preheated at $120{ }^{\circ} \mathrm{C}$ for $5 \mathrm{~min}$ ) containing $0.383 \mathrm{~g}(1.00 \mathrm{mmol})$ of 1 -[ $N, N$-di(4-carboxyphenyl)amino]naphthalene and $0.228 \mathrm{~g}(1.00 \mathrm{mmol})$ of $4,4^{\prime}$-isopropylidenediphenol ( $\left.3 \mathrm{~b}\right)$ in pyridine $(2.0 \mathrm{~mL})$. The final solution was heated with stirring at $120^{\circ} \mathrm{C}$ for $3 \mathrm{~h}$. The obtained polymer solution was poured slowly into $200 \mathrm{~mL}$ of stirred water giving rise to a stringy, fiberlike precipitate that was collected by filtration, washed thoroughly with hot water and methanol, and dried under vacuum at $100{ }^{\circ} \mathrm{C}$. Reprecipitations of the polymer by $\mathrm{N}, \mathrm{N}$-dimethylacetamide (DMAc)/methanol were carried out twice for further purification. These polymers collected by filtration and dried at $120{ }^{\circ} \mathrm{C}$ under vacuum. The inherent viscosity and weightaverage molecular weights $\left(M_{\mathrm{w}}\right)$ of the obtained polyarylate Ib was $0.46 \mathrm{dL} / \mathrm{g}$ (measured at a concentration of $0.5 \mathrm{~g} / \mathrm{dL}$ in DMAc at $30^{\circ} \mathrm{C}$ ) and 28,500 daltons, respectively. ${ }^{1} \mathrm{H}$ NMR $\left(\mathrm{CDCl}_{3}, \delta, \mathrm{ppm}\right): 1.71$ (s, 6H, methyl), $7.10\left(\mathrm{~d}, 4 \mathrm{H}, \mathrm{H}_{\mathrm{j}}\right), 7.17$ $\left(\mathrm{d}, 4 \mathrm{H}, \mathrm{H}_{\mathrm{b}}\right), 7.28\left(\mathrm{~d}, 4 \mathrm{H}, \mathrm{H}_{\mathrm{k}}\right), 7.43\left(\mathrm{~m}, 2 \mathrm{H}, \mathrm{H}_{\mathrm{c}}+\mathrm{H}_{\mathrm{h}}\right), 7.54(\mathrm{t}$, $\left.2 \mathrm{H}, \mathrm{H}_{\mathrm{d}}+\mathrm{H}_{\mathrm{g}}\right), 7.83\left(\mathrm{~d}, 1 \mathrm{H}, \mathrm{H}_{\mathrm{i}}\right), 7.91\left(\mathrm{~d}, 1 \mathrm{H}, \mathrm{H}_{\mathrm{e}}\right), 7.96(\mathrm{~d}, 1 \mathrm{H}$, $\left.\mathrm{H}_{\mathrm{f}}\right), 8.06\left(\mathrm{~d}, 4 \mathrm{H}, \mathrm{H}_{\mathrm{a}}\right) .{ }^{13} \mathrm{C} \mathrm{NMR}\left(\mathrm{CDCl}_{3}, \delta, \mathrm{ppm}\right): 30.9$ (methyl), $42.5\left(C^{19}\right), 120.9\left(C^{3}\right), 121.1\left(C^{16}\right), 123.0\left(C^{1}\right), 123.3\left(C^{13}\right)$, $126.4\left(C^{7}\right), 126.6\left(C^{11}\right), 127.2\left(C^{12}\right), 127.8\left(C^{6}+C^{17}\right), 128.2$ $\left(C^{8}\right), 128.7\left(C^{10}\right), 130.8\left(C^{14}\right), 131.7\left(C^{2}\right), 135.3\left(C^{9}\right), 141.4$ $\left(C^{5}\right), 147.8\left(C^{18}\right), 148.8\left(C^{4}\right), 151.5\left(C^{15}\right)$, and 164.7 (ester carbonyl). The elemental analysis values of polyarylate Ic was calculated for $\left(\mathrm{C}_{39} \mathrm{H}_{23} \mathrm{~F}_{6} \mathrm{NO}_{4}\right)_{n}(683.59)_{n}$ : C, 68.52\%; $\mathrm{H}$ : 3.39\%; N: 2.05\%. Found for C, $68.50 \%$; H, 3.95\%; N, $2.01 \%$. The other polyarylates (see Scheme 1 ) were synthesized by a similar procedure described as above.

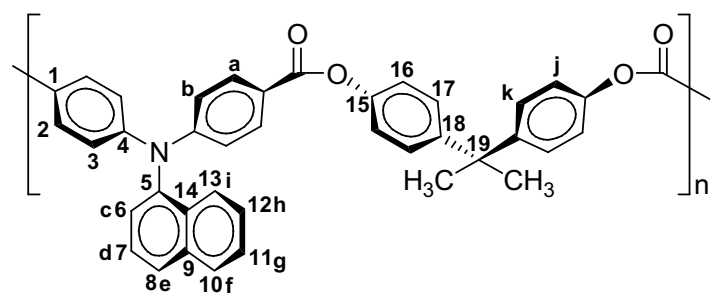




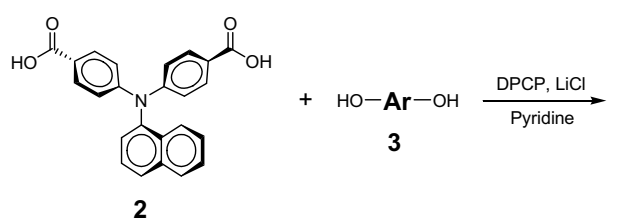<smiles>CCC(C)O[Al]OC(=O)c1ccc(N(c2ccccc2)c2ccc(C)cc2)cc1</smiles><smiles>O=C(O)c1ccc(N(c2ccccc2)c2ccc(C(=O)O)cc2)cc1</smiles><smiles>Cc1cccn1-c1ccc(O[Te]OC(C)(C)C)cc1</smiles>

Ar:
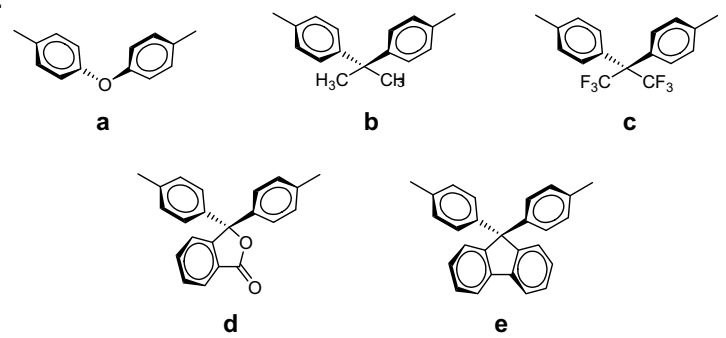

Scheme 1. Synthesis of aromatic polyarylates.

\subsubsection{Preparation of the polyarylates films}

A solution of polymer was made by dissolving about $0.5 \mathrm{~g}$ of the polyarylates sample in $8 \mathrm{~mL}$ of DMAc. The homogeneous solution was poured into a 9-cm glass Petri dish, which was heated at $80^{\circ} \mathrm{C}$ for $1 \mathrm{~h}$ and $160^{\circ} \mathrm{C}$ for $5 \mathrm{~h}$ to slowly release the solvent under vacuum. The obtained films were about $50-70 \mu \mathrm{m}$ in thickness and were used for molecular weights measurements, solubility tests, thermal analyses, optical and electrochemical properties measurements.

\subsection{Measurements}

Infrared spectra were recorded on a Perkin-Elmer RXI FT-IR spectrometer. Elemental analyses were run in VarioEL-III Elementar. ${ }^{1} \mathrm{H}$ and ${ }^{13} \mathrm{C}$ nuclear magnetic resonance (NMR) spectra were measured on a Varian Unity Inova 300 FT-NMR system and referenced to the $\mathrm{CDCl}_{3}$ signal, and peak multiplicity was reported as follows: s, singlet; $\mathrm{d}$, doublet; $\mathrm{t}$, triplet; $\mathrm{m}$, multiplet. The inherent viscosities were determined at $0.5 \mathrm{~g} / \mathrm{dL}$ concentration using Tamson TV-2000 viscometer at $30^{\circ} \mathrm{C}$. Gel permeation chromatographic (GPC) analysis was performed on a Lab Alliance RI2000 instrument (two column, MIXED-C and D from Polymer Laboratories) connected with one refractive index detector from Schambeck SFD Gmbh. All GPC analyses were performed using a polymer/THF solution at a flow rate of $1 \mathrm{~mL} / \mathrm{min}$ at $40{ }^{\circ} \mathrm{C}$ and calibrated with polystyrene standards. Differential scanning calorimetry (DSC) analyses were performed on a Perkin-Elmer Pyris Diamond DSC at a scan rate of $20^{\circ} \mathrm{C} / \mathrm{min}$ in flowing nitrogen $\left(20 \mathrm{~cm}^{3} / \mathrm{min}\right)$. Thermomechanical analysis (TMA) was conducted with a Perkin-Elmer TMA 7 instrument. The TMA experiments were conducted from 50 to $350^{\circ} \mathrm{C}$ at a scan rate of $10^{\circ} \mathrm{C} / \mathrm{min}$ with a penetration probe $1.0 \mathrm{~mm}$ in diameter under an applied constant load of $50 \mathrm{mN}$. Softening temperatures $\left(T_{\mathrm{s}}\right)$ were taken as the onset temperatures of probe displacement on the TMA traces. Thermogravimentric analysis (TGA) was conducted with a Perkin-Elmer Pyris 1 TGA. Experiments were carried out on approximately 6-8 $\mathrm{mg}$ film samples heated in flowing nitrogen or air (flow rate $=20 \mathrm{~cm}^{3} / \mathrm{min}$ ) at a heating rate of $20^{\circ} \mathrm{C} / \mathrm{min}$. Ultraviolet-visible (UV-vis) spectra of the polymer films were recorded on a Varian Cary 50 Probe spectrometer. Absorption spectra were measured with a HP 8453 UV-visible spectrophotometer. Photoluminescence spectra were measured with a Jasco FP-6300 spectrofluorometer. The fluorescence quantum yields $\left(\Phi_{\mathrm{PL}}\right)$ of polymer solution were determined in THF against quinine sulfate (ACROS) in $1 \mathrm{~N} \mathrm{H}_{2} \mathrm{SO}_{4(\mathrm{aq})}$ as the standard

Table 1

Inherent viscosity ${ }^{\mathrm{a}}$ and molecular weights ${ }^{\mathrm{b}}$ of polyarylates

\begin{tabular}{llllll}
\hline Polymer & $\eta_{\text {inh }}(\mathrm{dL} / \mathrm{g})$ & $M_{\mathrm{w}}$ & $M_{\mathrm{n}}$ & $\mathrm{PDI}^{\mathrm{c}}$ & $\mathrm{DP}^{\mathrm{d}}$ \\
\hline Ia & $0.35[0.41]^{\mathrm{e}}$ & 31,500 & 18,500 & 1.70 & 33.7 \\
Ib & $0.46[0.25]$ & 28,500 & 17,000 & 1.68 & 29.5 \\
Ic & $0.27[0.27]$ & 33,400 & 19,300 & 1.73 & 28.2 \\
Id & $0.25[0.23]$ & 31,800 & 18,800 & 1.69 & 28.2 \\
Ie & $0.31[0.30]$ & 28,300 & 16,800 & 1.68 & 24.1 \\
\hline
\end{tabular}

${ }^{\text {a }}$ Measured at a polymer concentration of $0.5 \mathrm{~g} / \mathrm{dL}$ in DMAc at $30^{\circ} \mathrm{C}$.

b Calibrated with polystyrene standards, using THF as the eluent at a constant flow rate of $1 \mathrm{~mL} / \mathrm{min}$ at $40^{\circ} \mathrm{C}$.

${ }^{c}$ Polydispersity index $\left(M_{\mathrm{w}} / M_{\mathrm{n}}\right)$.

${ }^{d}$ Degree of polymerization.

e Data in the parentheses are polyarylates $\mathbf{I}^{\prime}$ series. 
$\left(\Phi_{\mathrm{PL}}=0.546\right)[20]$ were used. All corrected fluorescence excitation spectra were found to be equivalent to their respective absorption spectra. Electrochemistry was performed with a CHI 611B electrochemical analyzer. Cyclic
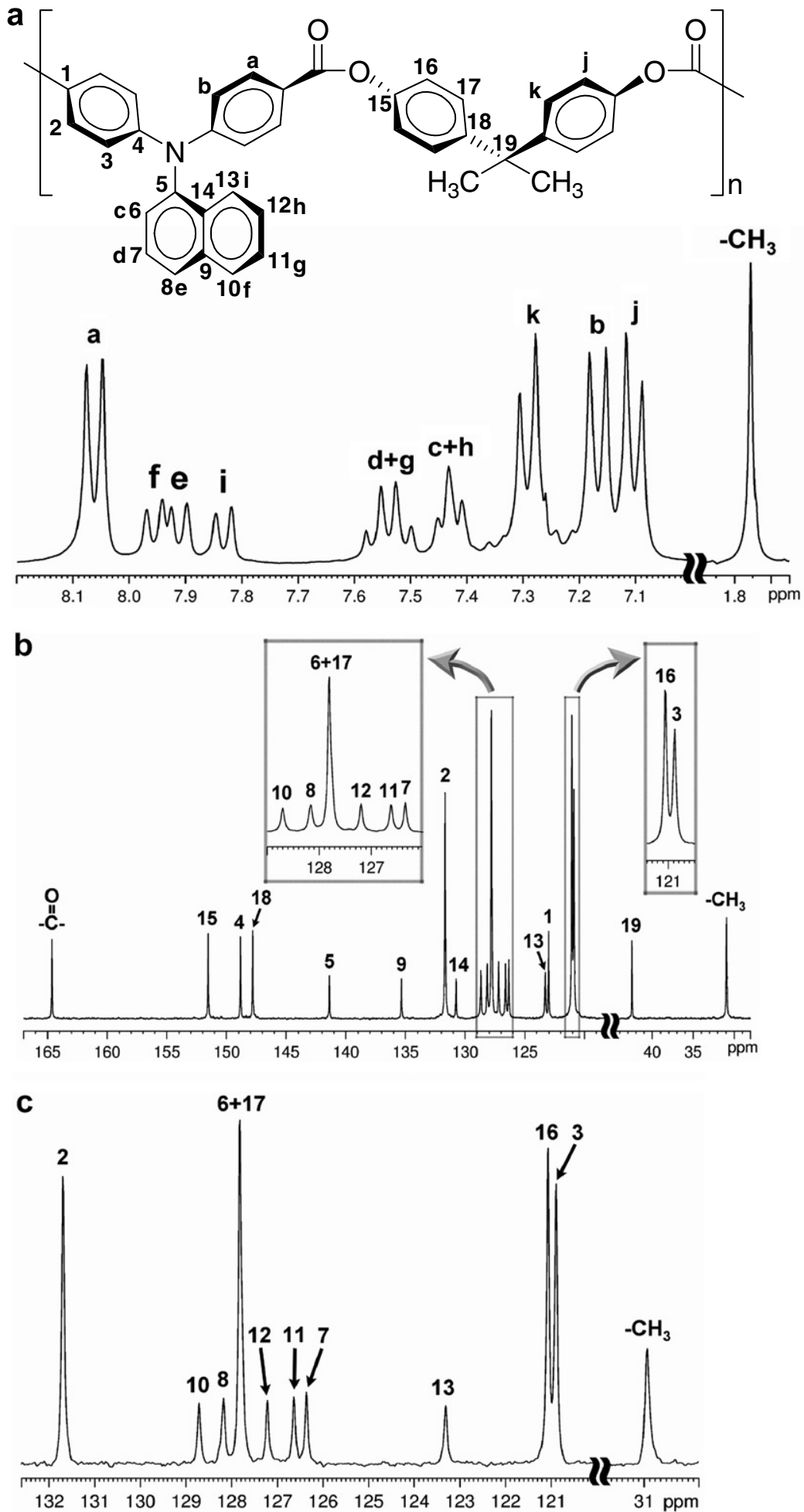

Fig. 1. (a) ${ }^{1} \mathrm{H}$ NMR, (b) ${ }^{13} \mathrm{C}$ NMR and (c) DEPT-135 spectra of polyarylate Ib in $\mathrm{CDCl}_{3}$. 
voltammetry was conducted with the use of a three-electrode cell in which ITO (polymer films area about $0.7 \mathrm{~cm} \times 0.5 \mathrm{~cm}$ ) was used as a working electrode and a platinum wire was used as an auxiliary electrode at a scan rate of $100 \mathrm{mV} / \mathrm{s}$ against a $\mathrm{Ag} / \mathrm{AgCl}$ reference electrode in solution of $0.1 \mathrm{M}$ tetrabutylammonium perchlorate (TBAP)/acetonitrile $\left(\mathrm{CH}_{3} \mathrm{CN}\right)$. Voltammograms are presented with the positive potential pointing to the left and with increasing anodic currents pointing downwards. All cell potentials were taken with the use of a home-made $\mathrm{Ag} / \mathrm{AgCl}, \mathrm{KCl}$ (sat.) reference electrode.

\section{Results and discussion}

\subsection{Polymer synthesis}

A series of novel polyarylates with bulky pendent naphthylamine chromophores were prepared from the dicarboxylic acids, 1-[N,N-di(4-carboxyphenyl)amino]naphthalene (2), and various aromatic diols (3) by the direct polycondensation reaction with DPCP and pyridine as condensing agents [21] (Scheme 1). All the polymerizations proceeded homogeneously throughout the reaction and afforded clear, moderately high viscous polymer solutions. All of the polymers precipitated in a fiber-like form when the resulting polymer solutions were slowly poured into water. These polyarylates were obtained in almost quantitative yields with inherent viscosity values in the range of $0.25-0.46 \mathrm{dL} / \mathrm{g}\left(0.23-0.41 \mathrm{dL} / \mathrm{g}\right.$ for series $\left.\mathbf{I}^{\prime}\right)$ and with weight-average molecular weights $\left(M_{\mathrm{w}}\right)$ and degree of polymerization (DP) in the range of 28,300-33,400 daltons and 24.1-33.7, respectively, relative to polystyrene standards (Table 1). The formation of polyarylates was confirmed by elemental analysis, IR, ${ }^{1} \mathrm{H}$ and ${ }^{13} \mathrm{C}$ NMR spectroscopy. Most polyarylates could be solution-cast into good quality, transparent and colorless films. The structural feature of the polyarylates was confirmed by IR spectroscopy. The characteristic absorptions of ester group appear around $1735 \mathrm{~cm}^{-1}$ ( $\mathrm{C}=\mathrm{O}$ stretching) and in the region of $1200-1300 \mathrm{~cm}^{-1}$ (C-O stretching). Fig. 1 show a typical set of ${ }^{1} \mathrm{H}$ NMR, ${ }^{13} \mathrm{C}$ NMR and DEPT-135 spectra of polyarylate Ib in $\mathrm{CDCl}_{3}$. The ${ }^{13} \mathrm{C}$ NMR spectras of<smiles>CC(C)(C)c1ccc(N(c2ccc(C(=O)O)cc2)c2cccc3ccccc23)cc1</smiles><smiles>CC(C)(c1ccccc1)c1ccc(OC(=O)CC2CCCCC2)cc1</smiles>

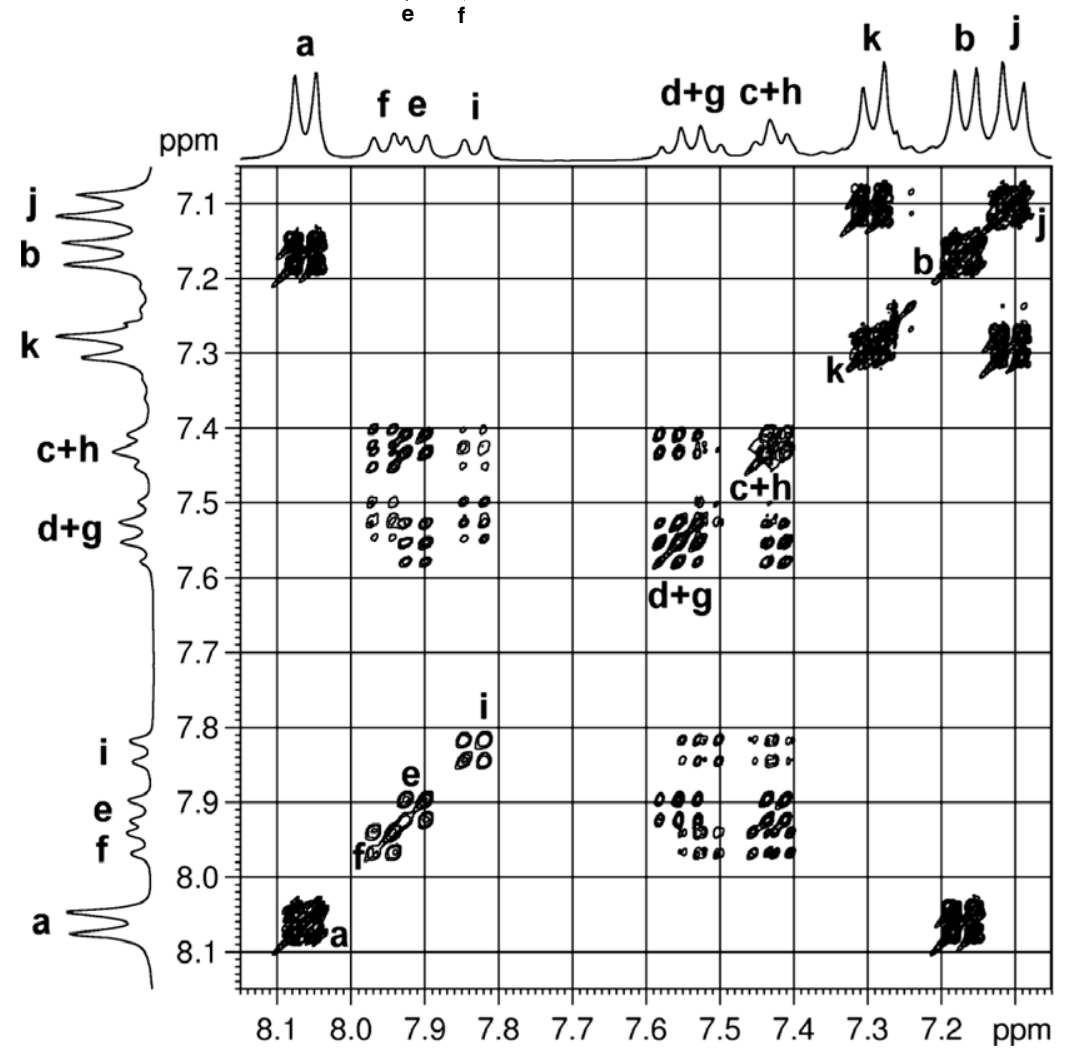

Fig. 2. $\mathrm{H}-\mathrm{H} \operatorname{COSY}$ (Correlation Spectroscopy) spectra of polyarylate $\mathbf{I b}$ in $\mathrm{CDCl}_{3}$. 
polyarylate Ib confirmed that the signal at $164.7 \mathrm{ppm}$ corresponding to the ester carbonyl carbon. All the ${ }^{13} \mathrm{C}$ atoms in polyarylate Ib resonated in the region of $120-155 \mathrm{ppm}$, and the singlet at $30.9 \mathrm{ppm}$ due to the $-\mathrm{CH}_{3}$ carbons. Assignments of each carbon and proton are assisted by the two-dimensional $\mathrm{H}-\mathrm{H}$ COSY (correlation spectroscopy) and $\mathrm{C}-\mathrm{H}$ HMQC (heteronuclear multiple quantum correlation) spectra shown in Figs. 2 and 3, and these spectra agree well with the proposed molecular structure of polyarylate Ib.

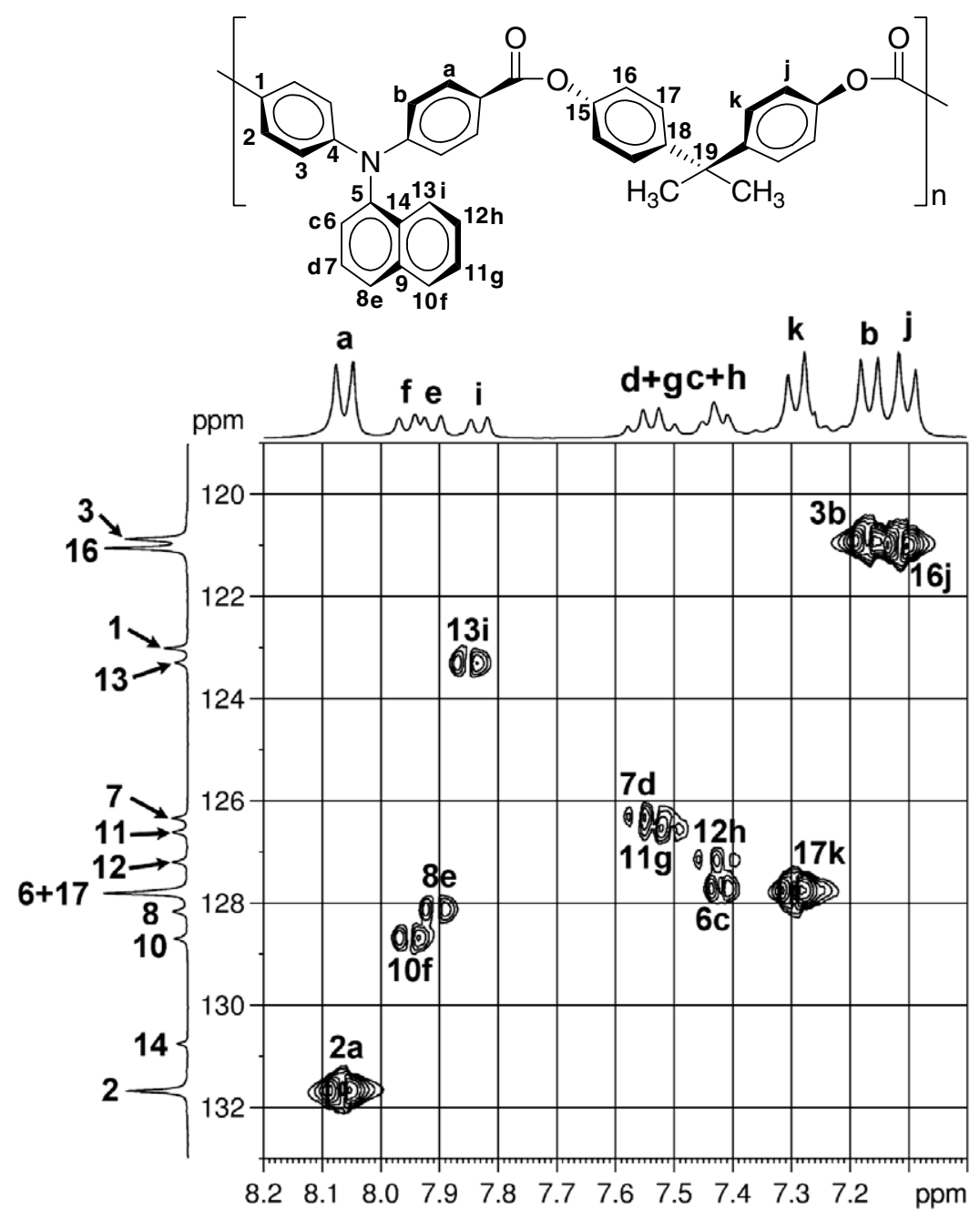

Fig. 3. C-H HMQC (Heteronuclear Multiple Quantum Correlation) spectra of polyarylate $\mathbf{I b}$ in $\mathrm{CDCl}_{3}$.

Table 2

Solubility ${ }^{\mathrm{a}}$ of polyarylates

\begin{tabular}{|c|c|c|c|c|c|c|c|c|}
\hline \multirow[t]{2}{*}{ Polymer code } & \multicolumn{8}{|c|}{ Solvent } \\
\hline & NMP & DMAC & DMF & $m$-Cresol & THF & $\mathrm{CHCl}_{3}$ & Toluene & $\mathrm{CH}_{3} \mathrm{CN}$ \\
\hline Ia & ++ & ++ & ++ & ++ & ++ & ++ & + & - \\
\hline Ib & ++ & ++ & ++ & ++ & ++ & ++ & + & - \\
\hline Ic & ++ & ++ & ++ & ++ & ++ & ++ & ++ & - \\
\hline Id & ++ & ++ & ++ & ++ & ++ & ++ & +- & - \\
\hline Ie & ++ & ++ & ++ & ++ & ++ & ++ & + & - \\
\hline I'a & ++ & + & +- & +- & + & ++ & +- & - \\
\hline $\mathbf{I}^{\prime} \mathbf{b}$ & ++ & ++ & ++ & + & ++ & ++ & ++ & - \\
\hline$I^{\prime} \mathbf{c}$ & ++ & ++ & ++ & + & ++ & ++ & ++ & - \\
\hline$I^{\prime} d$ & ++ & ++ & ++ & + & ++ & ++ & +- & - \\
\hline $\mathbf{I}^{\prime} \mathbf{e}$ & ++ & ++ & +- & +- & ++ & ++ & +- & - \\
\hline
\end{tabular}

++: soluble at room temperature; +: soluble on heating; +-: partial soluble or swelling on heating; -: insoluble even on heating.

a The solubility was determined by using $1 \mathrm{mg}$ sample in $1 \mathrm{~mL}$ of solvent. 


\subsection{Polymer properties}

\subsubsection{Basic characterizations}

The solubility behavior of the polyarylates was tested qualitatively, and the results are summarized in Table 2 . These high transparency polyarylates were very easily soluble in many common organic solvents such as NMP, DMAc, $N, N$-dimethylformamide (DMF), $m$-cresol, THF and chloroform $\left(\mathrm{CHCl}_{3}\right)$ and the solubility is somewhat much better than series $\mathbf{I}^{\prime}$. The solubility is really enhanced just like the aforementioned reason in the introduction. The more bulky pendent naphthylamine chromophores in the repeating unit surely play an important role to increase more free volume in the polymer chains so as to allow more solvent to come in. Thus, the excellent solubility makes these polymers convenient to processing into articles by spin- or dip-coating.

\subsubsection{Thermal properties}

The thermal properties of the polyarylates were investigated by DSC, TMA and TGA. The results are summarized in Table 3. The $T_{\mathrm{g}}$ of all the polyarylates could be easily measured in the DSC thermograms; they were observed in the range of $216-310^{\circ} \mathrm{C}$, depend on the structure of bisphenol components, and decreased with decreasing rigidity and symmetry of the polymer backbone. In addition, polymer Id and Ie containing a bulky group in bisphenol had the higher $T_{\mathrm{g}}$ value. All the polyarylates exhibited good thermal stability with insignificant weight loss up to $505^{\circ} \mathrm{C}$ in nitrogen. The $10 \%$ weight-loss temperatures $\left(T_{d}^{10}\right)$ of these polyarylates in nitrogen and air were recorded in the range of $520-555$ and $505-535{ }^{\circ} \mathrm{C}$, respectively. The amount of carbonized residue (char yield) of these polymers in nitrogen atmosphere was more than 50\% at $800^{\circ} \mathrm{C}$. The high char yields of these polymers can be ascribed to their high aromatic content.

Table 3

Thermal properties ${ }^{\mathrm{a}}$ of polyarylates

\begin{tabular}{|c|c|c|c|c|c|c|c|}
\hline \multirow[t]{2}{*}{ Polymer } & \multirow[t]{2}{*}{$T_{\mathrm{g}}\left({ }^{\circ} \mathrm{C}\right)^{\mathrm{b}}$} & \multirow[t]{2}{*}{$T_{\mathrm{s}}\left({ }^{\circ} \mathrm{C}\right)^{\mathrm{c}}$} & \multicolumn{2}{|c|}{$T_{\mathrm{d}}^{5}\left({ }^{\circ} \mathrm{C}\right)^{\mathrm{d}}$} & \multicolumn{2}{|c|}{$T_{\mathrm{d}}{ }^{10}\left({ }^{\circ} \mathrm{C}\right)^{\mathrm{e}}$} & \multirow[t]{2}{*}{ Char yield (wt\%) } \\
\hline & & & $\mathrm{N}_{2}$ & Air & $\mathrm{N}_{2}$ & Air & \\
\hline Ia & 216 & 216 & 520 & 495 & 540 & 510 & 57 \\
\hline Ib & 248 & 243 & 515 & 475 & 535 & 505 & 50 \\
\hline Ic & 239 & 240 & 505 & 490 & 525 & 505 & 57 \\
\hline Id & 310 & 317 & 505 & 490 & 520 & 505 & 60 \\
\hline Ie & 304 & 299 & 535 & 505 & 555 & 535 & 64 \\
\hline$I^{\prime} \mathbf{a}$ & 186 & 183 & 485 & 480 & 500 & 495 & 42 \\
\hline $\mathbf{I}^{\prime} \mathbf{b}$ & 203 & 206 & 465 & 460 & 480 & 480 & 32 \\
\hline$I^{\prime} \mathbf{c}$ & 206 & 206 & 480 & 470 & 495 & 485 & 52 \\
\hline$I^{\prime} \mathbf{d}$ & 246 & 246 & 475 & 470 & 495 & 495 & 48 \\
\hline$I^{\prime} \mathbf{e}$ & 254 & 255 & 485 & 480 & 515 & 505 & 45 \\
\hline
\end{tabular}

a The polymer film samples were heated at $200^{\circ} \mathrm{C}$ for $1 \mathrm{~h}$ prior to all the thermal analyses.

b Midpoint temperature of baseline shift on the second DSC heating trace (rate: $20^{\circ} \mathrm{C} / \mathrm{min}$ ) of the sample after quenching from 400 to $50{ }^{\circ} \mathrm{C}$ (rate: $200{ }^{\circ} \mathrm{C} /$ min) in nitrogen.

c Softening temperature measured by TMA with a constant applied load of $50 \mathrm{mN}$ at a scan rate of $10{ }^{\circ} \mathrm{C} / \mathrm{min}$.

d Temperature at which $5 \%$ weight loss occurred, recorded via TGA at a heating rate of $20{ }^{\circ} \mathrm{C} / \mathrm{min}$ and a gas-flow rate of $20 \mathrm{~cm}{ }^{3} / \mathrm{min}$.

e Temperature at which $10 \%$ weight loss occurred.

${ }^{\mathrm{f}}$ Residual weight percentage at $800{ }^{\circ} \mathrm{C}$ in nitrogen.

\section{Table 4}

Optical and electrochemical properties of polyarylates

\begin{tabular}{|c|c|c|c|c|c|c|c|c|c|c|c|c|}
\hline \multirow[t]{2}{*}{ Index } & \multicolumn{3}{|c|}{ THF $\left(1 \times 10^{-5} \mathrm{M}\right)$ solution, R.T. } & \multicolumn{4}{|c|}{ Film (nm), R.T. } & \multicolumn{2}{|c|}{ Oxidation $/ \mathrm{V}^{\mathrm{d}}$} & \multirow[t]{2}{*}{$E_{\mathrm{g}}^{\mathrm{f}}(\mathrm{eV})$} & \multirow[t]{2}{*}{$E_{\text {номо }}(\mathrm{eV})^{\mathrm{g}}$} & \multirow[t]{2}{*}{$\overline{E_{\text {LUMO }}(\mathrm{eV})}$} \\
\hline & $\lambda_{\max }$ & $\lambda_{\mathrm{em}}{ }^{\mathrm{a}}$ & $\Phi_{\mathrm{PL}}(\%)^{\mathrm{b}}$ & $\lambda_{0}{ }^{c}$ & $\lambda_{\max }$ & $\lambda_{\text {onset }}$ & $\lambda_{\mathrm{em}}^{\mathrm{a}}$ & $E_{\text {onset }}$ & $E_{1 / 2} \mathrm{e}$ & & & \\
\hline Ia & 355 & 428 & 28.1 & 390 & 357 & 390 & 448 & 1.31 & 1.36 & 3.18 & 5.67 & 2.49 \\
\hline Ib & 354 & 426 & 34.9 & 390 & 354 & 392 & 448 & 1.31 & 1.36 & 3.16 & 5.67 & 2.51 \\
\hline Ic & 357 & 437 & 30.4 & 385 & 358 & 392 & 446 & 1.30 & 1.36 & 3.16 & 5.66 & 2.50 \\
\hline Id & 356 & 433 & 32.7 & 390 & 356 & 395 & 450 & 1.28 & 1.37 & 3.14 & 5.64 & 2.50 \\
\hline Ie & 356 & 428 & 33.4 & 390 & 358 & 394 & 449 & 1.30 & 1.35 & 3.15 & 5.66 & 2.51 \\
\hline$I^{\prime} \mathbf{a}$ & 359 & 432 & 32.6 & 396 & 363 & 403 & 442 & 1.27 & 1.33 & 3.08 & 5.59 & 2.51 \\
\hline$I^{\prime} \mathbf{b}$ & 360 & 427 & 26.3 & 390 & 363 & 398 & 441 & 1.34 & 1.40 & 3.12 & 5.66 & 2.54 \\
\hline$I^{\prime} \mathbf{C}$ & 364 & 436 & 28.9 & 389 & 365 & 400 & 444 & 1.36 & 1.41 & 3.10 & 5.68 & 2.58 \\
\hline$I^{\prime} \mathbf{d}$ & 362 & 435 & 30.7 & 391 & 365 & 402 & 450 & 1.29 & 1.35 & 3.08 & 5.61 & 2.53 \\
\hline$I^{\prime} \mathbf{e}$ & 362 & 427 & 27.6 & 388 & 365 & 398 & 443 & 1.33 & 1.37 & 3.12 & 5.65 & 2.53 \\
\hline
\end{tabular}

a They were excited at $\lambda_{\mathrm{abs}}$ for both solid and solution states.

b The quantum yield was measured by using quinine sulfate (dissolved in $1 \mathrm{~N} \mathrm{H}_{2} \mathrm{SO}_{4}$ with a concentration of $10^{-5} \mathrm{M}$, assuming photoluminescence quantum efficiency of 0.546 ) as a standard at $24-25^{\circ} \mathrm{C}$.

${ }^{c}$ The cutoff wavelength $\left(\lambda_{0}\right)$ from the UV-vis transmission spectra of polymer films (thickness: 1-3 $\mu \mathrm{m}$ ).

${ }^{d}$ vs. $\mathrm{Ag} / \mathrm{AgCl}$ in $\mathrm{CH}_{3} \mathrm{CN}_{(1)}$.

e $E_{1 / 2}$ (average potential of the redox couple peaks).

f The data were calculated from polymer films by the equation: $E_{\mathrm{g}}=1240 / \lambda_{\text {onset }}$ (energy gap between HOMO and LUMO).

$g$ The HOMO energy levels were calculated from cyclic voltammetry and were referenced to ferrocene ( $4.8 \mathrm{eV})$. 
Comparing the thermal properties data of polyarylates I and $\mathbf{I}^{\prime}$ in Table 3. One will find, that in series $\mathbf{I}$, not only the $T_{\mathrm{g}}, T_{\mathrm{s}}$ and $T_{\mathrm{d}}$ but also the char yield is superior than series $\mathbf{I}^{\prime}$. It means that the bulky naphthylamine chromophores are more effectively preserving the thermal stability in the prepared polyarylates.

\subsubsection{Optical properties and electrochemical properties}

The optical and electrochemical properties of the polyarylates were investigated by UV-vis and photoluminescence spectroscopy and cyclic voltammetry. The results are summarized in Table 4. These polymers exhibited strong UV-vis absorption bands at 354-357 nm in THF solution (Fig. 4), combine the $n-\pi$ transitions resulting from the conjugation between the aromatic rings and nitrogen atoms with the characteristic $\pi-\pi^{*}$ transitions of naphthalene chromophore (350 nm) [22]. The fluorescence spectra of the polyarylates in THF solutions (Conc.: $10^{-5} \mathrm{M}$ ) exhibited emission maxima at $426-437 \mathrm{~nm}$ in the blue light region. The quantum yields of these polymers after refractive index correction can be calculated according to Eq. (1) [23]:

$\phi_{\text {unk }}=\phi_{\text {std }}\left(\frac{I_{\text {unk }}}{I_{\text {std }}}\right)\left(\frac{A_{\text {unk }}}{A_{\text {unk }}}\right)\left(\frac{\eta_{\text {unk }}}{\eta_{\text {std }}}\right)^{2}$,

where $\psi_{\text {unk }}, \psi_{\text {std }}, I_{\text {unk }}, I_{\text {std }}, A_{\text {unk }}, A_{\text {std }}, \eta_{\text {unk }}$, and $\eta_{\text {std }}$ are the fluorescent quantum yield, integration of the emission intensity, absorbance at the excitation wavelength, and the refractive indices of the corresponding solutions for the samples and the standard, respectively. Here we use the refractive indices of the pure solvents as those of the solutions. The PL quantum yield in THF solution ranges from $28.1 \%$ for Ia to $34.9 \%$ for Ib. The fluorescence quantum yield $\left(\Phi_{\mathrm{PL}}\right)$ of Ib $(0.349)$ measured in THF is the highest among this series polymers. This may be the result of the lesser electron-withdrawing capability of methyl $\left(-\mathrm{CH}_{3}\right)$

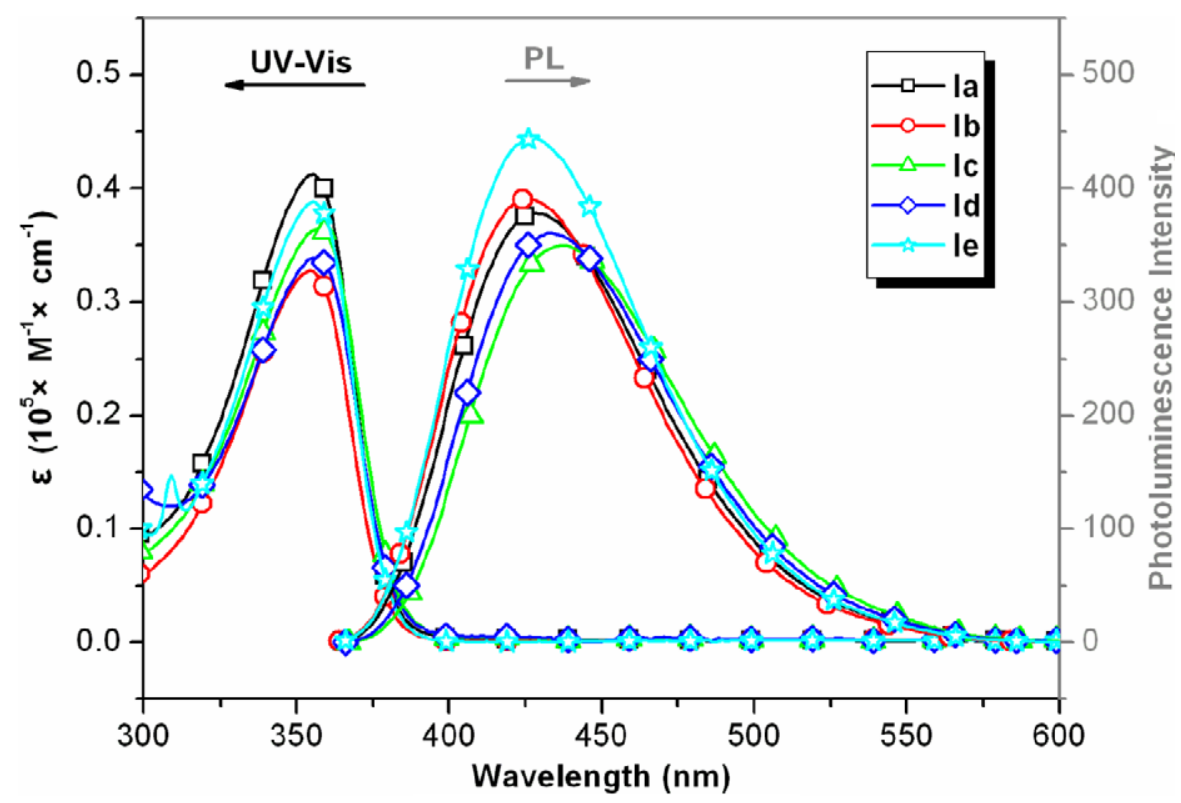

Fig. 4. UV-vis absorption and PL spectra of polyarylates in THF solution $\left(10^{-5} \mathrm{M}\right)$.

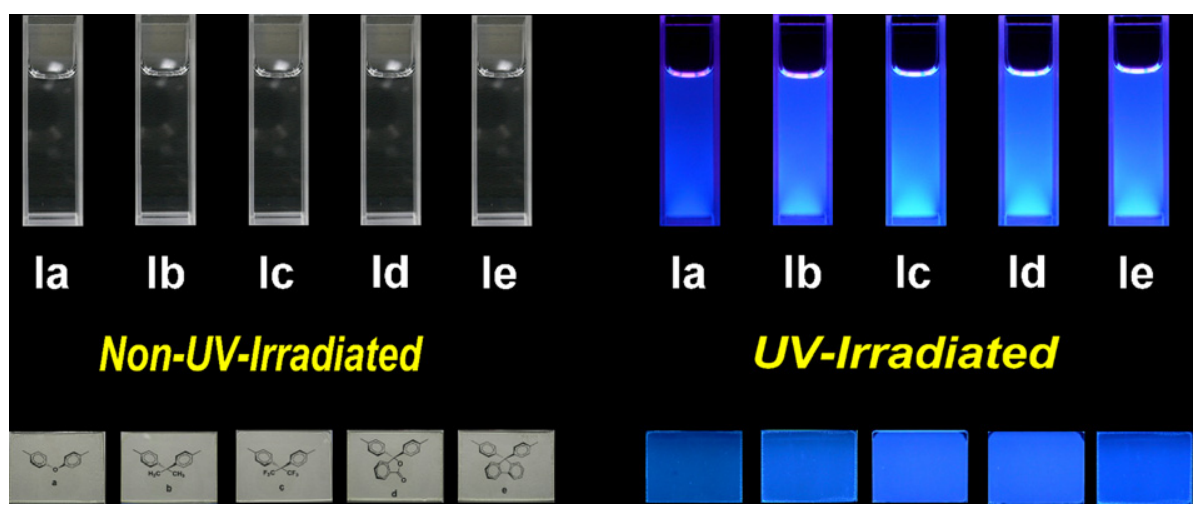

Fig. 5. The photoluminescence of polyarylates in THF solutions $\left(10^{-5} \mathrm{M}\right)$ and thin films (thickness: $\left.1-3 \mu \mathrm{m}\right)$ by UV irradiation (excited at $365 \mathrm{~nm}$ ). 
substituents in the bisphenol A of Ib, so the excited electrons will have more chance to come back to the ground state of naphthylamine chromophores. The solid-state emission spectra were similar to each other. The photoluminescence images of the polymer solution and thin film of polyarylates showed strong fluorescent blue light (Fig. 5). The UV-vis transmittance spectra of polyarylate films are also indicated in Table 4 . The cutoff wavelengths (absorption edge, $\lambda_{0}$ ) from the UV-vis transmittance spectra showed light-color and high optical transparency with cutoff wavelength in the range of 385-390 nm.

In Table 4, we can see that two series of polyarylates I and $\mathbf{I}^{\prime}$ does not exhibit significant difference in both optical and electrochemical properties except for the longer

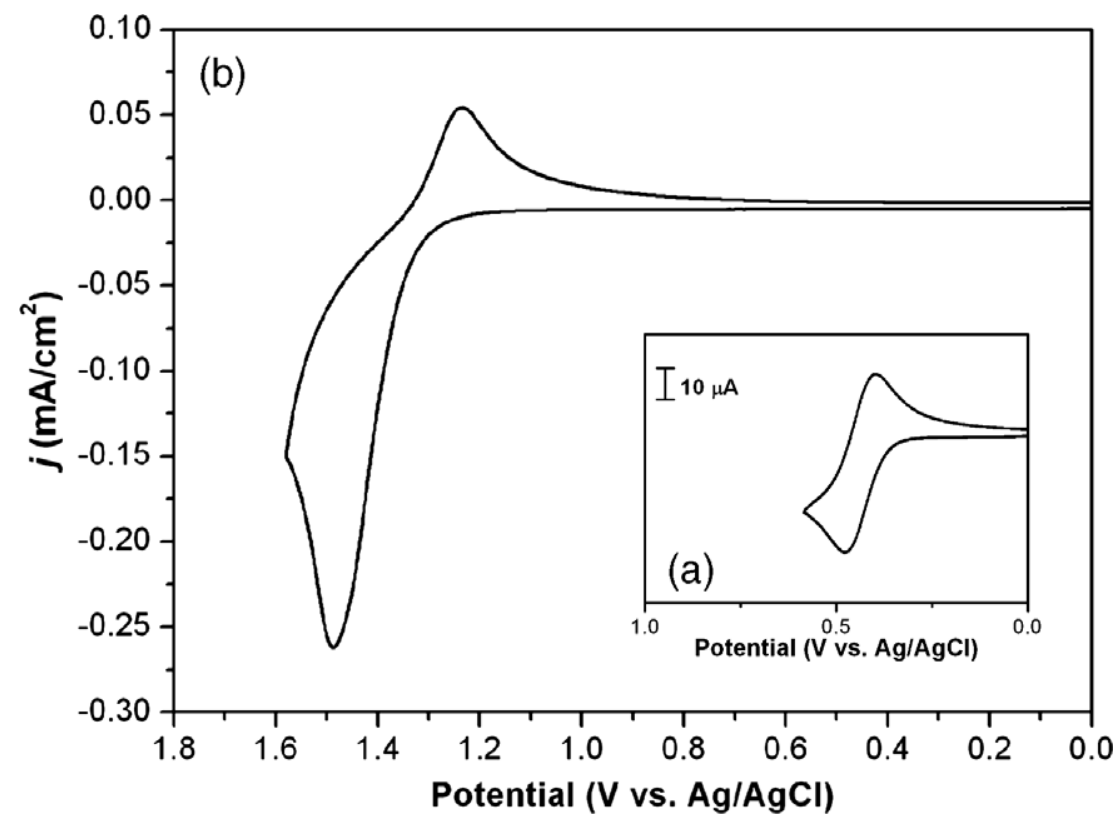

Fig. 6. Cyclic voltammograms of (a) ferrocene and (b) oxidation redox of polyarylate Ib film onto an indium-tin oxide (ITO)-coated glass substrate in $\mathrm{CH}_{3} \mathrm{CN}$ containing $0.1 \mathrm{M}$ TBAP. Scan rate $=0.1 \mathrm{~V} / \mathrm{s}$.

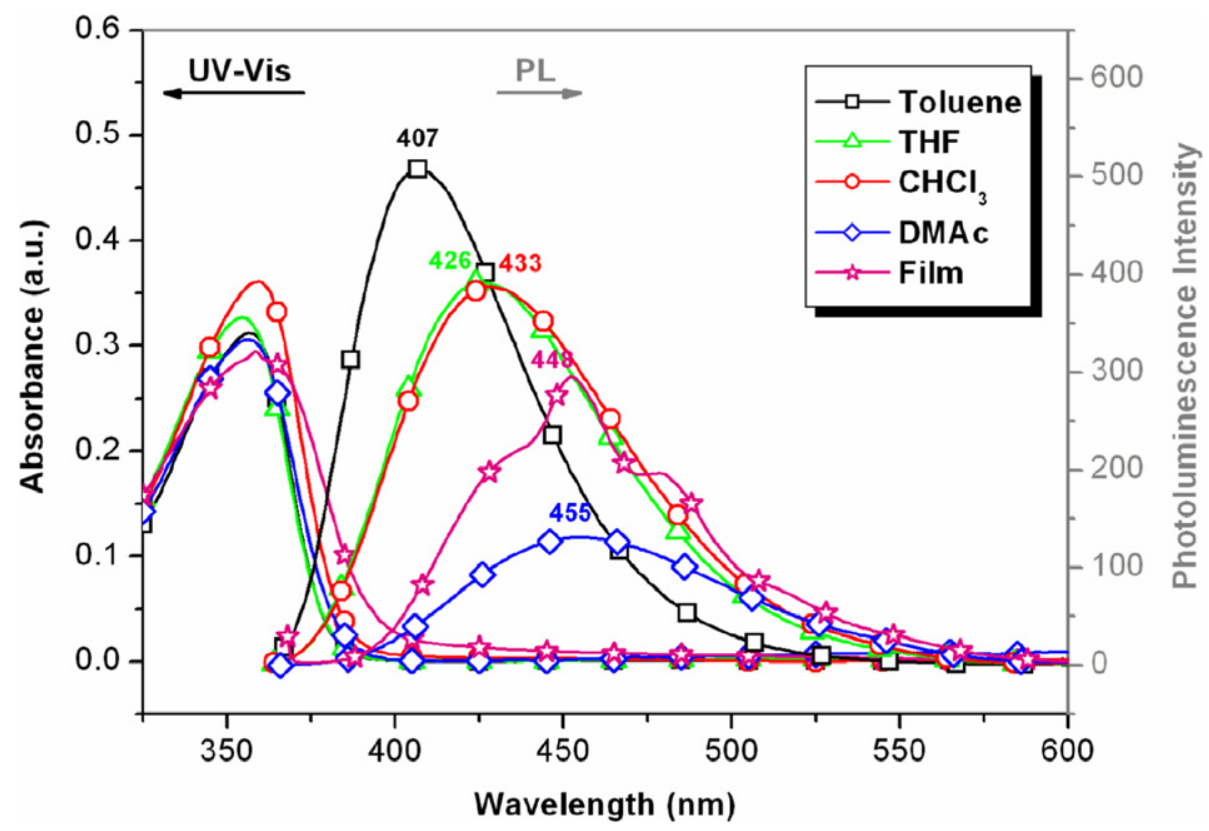

Fig. 7. UV-vis absorption and PL spectra of polyarylate Ib in different solvents: toluene, $\mathrm{THF}, \mathrm{CHCl}_{3}$ and $\mathrm{DMAc}$ (solution concentration is $10^{-5} \mathrm{M}$ and excited with abs $_{\max }$ respectively.) 
wavelength of $\lambda_{\text {onset }}$ and smaller $E_{\mathrm{g}}$ in $\mathbf{I}^{\prime}$ series. That is because the pendent naphthyl group is a stronger electron withdrawing group, so that the electron which want to escape from the highest occupied molecular orbital (HOMO) state of the series I need more energy than $\mathbf{I}^{\prime}$.

The electrochemical properties of the polyarylates were investigated by cyclic voltammetry (CV) and the data were summarized in Table 4, also. The oxidation redox behavior of these polyarylates was investigated by cyclic voltammetry conducted by the cast films on an ITO-coated glass substrate as working electrode in dry acetonitrile containing $0.1 \mathrm{M}$ of TBAP as an electrolyte under nitrogen atmosphere. The typical cyclic voltammogram for polyarylate Ib is shown in Fig. 6. The energy of the highest occupied molecular orbital (HOMO) and lowest unoccupied molecular orbital (LUMO) levels of the corresponding polyarylates can be determined from the oxidation onset potentials ( $\left.E_{\text {onset }}\right)$ and the onset absorption wavelength of the UVvis spectra, and the results are listed in Table 4. For example (Fig. 6), the oxidation onset potential for polyarylate Ib has been determined as $1.31 \mathrm{~V}$ vs $\mathrm{Ag} / \mathrm{AgCl}$. The external ferrocene/ferrocenium $\left(\mathrm{Fc} / \mathrm{Fc}^{+}\right)$redox standard $E_{1 / 2}$ is $0.44 \mathrm{~V}$ vs $\mathrm{Ag} / \mathrm{AgCl}$ in $\mathrm{CH}_{3} \mathrm{CN}$. Assuming that the HOMO energy for the $\mathrm{Fc} / \mathrm{Fc}^{+}$standard is $4.80 \mathrm{eV}$ with respect to the zero vacuum level, the HOMO and LUMO energy for polyarylate Ib has been evaluated to be 5.67 and $2.51 \mathrm{eV}$, respectively. The low-lying HOMO energy level of these polymers suggest that they have potential for use as hole-transporting and blue light-emitting materials in EL devices.

\subsubsection{Solvatochromism}

The photoluminescence spectra and images of polyarylate Ib were measured in different solvents (Figs. 7 and 8), and the fluorescence quantum yield $\left(\Phi_{\mathrm{PL}}\right)$ are listed in Table 5 . The absorption spectra of the four different solvents were very similar to each other. But the emission peak of the fluorescence spectra of Ib shifts to the longer wavelength side coincide with the increase of the polarity of the solvents was observed. The red-shift of the emission peaks, with PL emission maxima moving from 407 to $455 \mathrm{~nm}$ when the solvent is changed from toluene to DMAc (Fig. 7 and Table 5), which was probably due to dipole-dipole interactions of the excited state of the polymer with different solvent [24], and the fluorescence spectrum becomes broader with increasing polarity of the solvents.
The maximum fluorescence intensity of the Ib in toluene solution appeared at $407 \mathrm{~nm}$ with a highly quantum yield ( $\Phi_{\mathrm{PL}}$ ) of $41.0 \%$, which corresponds to the blue-purple light region. The maximum PL intensity of polyarylate film of Ib was observed at $448 \mathrm{~nm}$, which is perfectly blue in color. However, the red-shifted PL spectrum of polyarylate film, compared to the fluorescence spectrum of the solution in THF, is probably due to the stronger interactions between repeating units of the polymer in the solid state [25]. This phenomenon was also previously reported in our laboratory [18].

The solvatochromism is caused by photoinduced intramolecular charge transfer (ICT) in the excited state. Such chromic behavior is associated with the stabilization of the polar emissive excited states by the polar solvents [26]. The solvatochromic shifts of the emission spectra are much larger than those of absorption spectra, implying that the excited-state energy levels are influenced more than those in the electronic ground state [27].

According to this phenomenon, we also compared the polyarylates Ic and Ie with the structural similar polyarylates I'c and I'e (bearing triphenylamine groups in the main chain based on 4,4'-dicarboxytriphenylamine) about the solvatochromic behavior, but they showed opposite photoluminescent behavior in THF and Toluene. The photophysical properties of Ic, Ie, I'c, and I'e were measured and the results are listed in Table 6 . As we know, the pendent naphthyl group is bulkier than pendent phenyl group, so we can deduce that the Ic and Ie are easier to dissolve in Toluene than I'c and I'e do. When the electrons are excited to the LUMO state, they are more likely to come back to the HOMO state of Ic and Ie, just because that the HOMO state

Table 5

Photophysical properties of Ib in different solvents ${ }^{a}$

\begin{tabular}{llll}
\hline Solvent & $\lambda_{\max }(\mathrm{nm})$ & $\lambda_{\mathrm{PL}}(\mathrm{nm})$ & $\Phi_{\mathrm{PL}}(\%)^{\mathrm{b}}$ \\
\hline Toluene & 357 & 407 & 41.0 \\
$\mathrm{THF}$ & 354 & 426 & 34.9 \\
$\mathrm{CHCl}_{3}$ & 359 & 433 & 35.2 \\
$\mathrm{DMAc}$ & 356 & 455 & 17.1 \\
\hline
\end{tabular}

a Polymer concentration of $10^{-5} \mathrm{M}$ in different solvents.

b The quantum yield was measured by using quinine sulfate (dissolved in $1 \mathrm{~N} \mathrm{H}_{2} \mathrm{SO}_{4}$ with a concentration of $10^{-5} \mathrm{M}$, assuming photoluminescence quantum efficiency of 0.546 ) as a standard at $24-25{ }^{\circ} \mathrm{C}$.

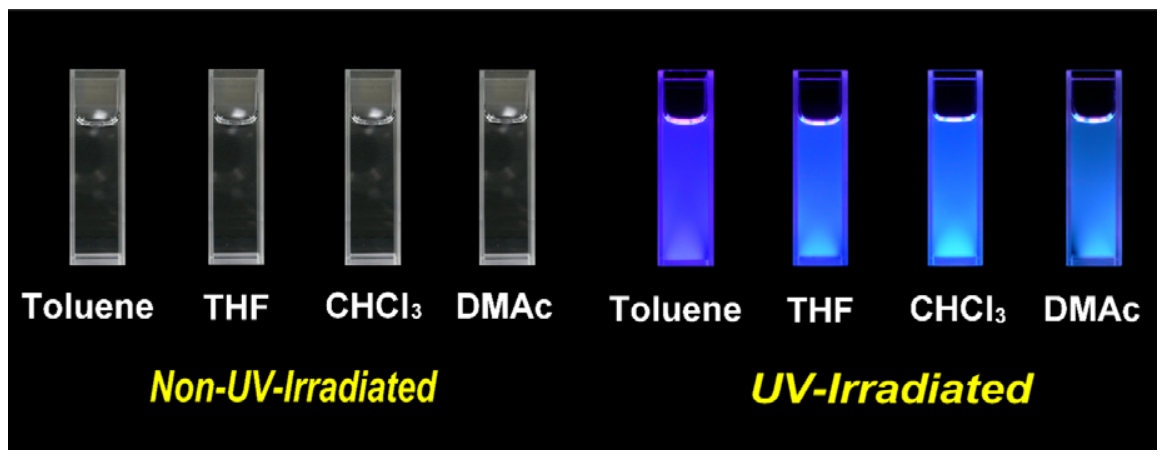

Fig. 8. The photoluminescence of polyarylate Ib in different solvent: toluene, $\mathrm{THF}, \mathrm{CHCl}_{3}$ and $\mathrm{DMAc}\left(10^{-5} \mathrm{M}\right)$ by $\mathrm{UV}$ irradiation (Excited at $\left.365 \mathrm{~nm}\right)$. 
Table 6

Photophysical properties of Ic, Ie, I'c, and I'e in different solvents ${ }^{\mathrm{a}}$

\begin{tabular}{|c|c|c|c|c|c|c|}
\hline \multirow[t]{2}{*}{ Code } & \multicolumn{3}{|l|}{ THF } & \multicolumn{3}{|l|}{ Toluene } \\
\hline & $\lambda_{\text {abs, } \max }(\mathrm{nm})$ & $\lambda_{\mathrm{PL}, \max }(\mathrm{nm})$ & $\Phi_{\mathrm{PL}}(\%)^{\mathrm{b}}$ & $\lambda_{\text {abs, } \max }(\mathrm{nm})$ & $\lambda_{\mathrm{PL}, \max }(\mathrm{nm})$ & $\overline{\Phi_{\mathrm{PL}}(\%)^{\mathrm{b}}}$ \\
\hline Ic & 357 & 437 & 30.4 & 359 & 414 & 38.6 \\
\hline Ie & 356 & 428 & 33.4 & 357 & 409 & 38.7 \\
\hline$I^{\prime} \mathbf{c}$ & 362 & 433 & 37.7 & 365 & 413 & 26.6 \\
\hline$I^{\prime} \mathbf{e}$ & 361 & 425 & 35.2 & 363 & 407 & 26.3 \\
\hline
\end{tabular}

a Polymer concentration of $10^{-5} \mathrm{M}$ in different solvents.

b The quantum yield in dilute solution was calculated in an integrating sphere with quinine sulfate as the standard $\left(\Phi_{\mathrm{PL}}=0.546\right)$.

are more stable for the electrons of Ic and Ie than they are in LUMO state. As for I'c and I'e, the excited electrons might be stabilized by the solvent and stay in the LUMO state for a longer time to result in poorer efficiency. That is maybe the reason why the two series of polyarylates exhibited opposite photoluminescent behavior in THF and toluene solution.

\section{Conclusions}

A novel series of blue photoluminescent aromatic polyesters (polyarylates) bearing pendent naphthylamine chromophores were synthesized from 1-[N,N-di(4-carboxyphenyl)amino]naphthalene with various bisphenols by the diphenylchlorophosphate (DPCP) activated direct polycondensation in a medium of pyridine and lithium chloride. The introduction of the bulky naphthylamine chromophores into the polymer backbone, which decreases the chain packing efficiency and increases the between-chains spaces, thus enhancing solubility, and the bulky ones do good for preserving the thermal stability of the formed polyarylates. These polyarylates were readily soluble in common organic solvents and could be cast into good quality films with moderately high $T_{\mathrm{g}}$ and thermal stability. All the polyarylates showed light color with high optical transparency from UV-vis transmittance measurement with cutoff wavelength in the range of $385-390 \mathrm{~nm}$, and exhibited blue photoluminescence both in film state (446-450 nm) and in THF solution (426-437 nm). Owing to their relatively high quantum efficiency in solution, thus, these polyarylates can be considered not only as new candidates for organo-processable high-performance polymeric materials in flat panel displays (FPDs) but also could be widely applied to the blue-light-emitting materials and even the source or host for generating of hybrid white light via the intermolecular charge transfer (ICT) or intramolecular energy transfer.

\section{Acknowledgment}

The authors are grateful to the National Science Council of the Republic of China for financial support of this work.

\section{References}

[1] Yang HH. Aromatic high-strength fiber. Interscience; 1989.

[2] Tang CW, VanSlyke SA. Appl Phys Lett 1987;51:913.

[3] Tang CW, VanSlyke SA, Chen CH. J Appl Phys 1989;85:3610.

[4] Adachi C, Nagai K, Tamoto N. Appl Phys Lett 1995;66:2679.

[5] Shirota Y. J Mater Chem 2000;10:1.

[6] Shirota Y. J Mater Chem 2005;15:79.

[7] Li XC, Liu YQ, Liu MS, Jen AKY. Chem Mater 1999;11:1568.

[8] Redecker M, Bradley DDC, Inbasekaran M, Wu WW, Woo EP. Adv Mater 1999;11:241.

[9] Ego C, Grimsdale AC, Uckert F, Yu G, Srdanov G, Mullen K. Adv Mater 2002;14:809.

[10] Shu CF, Dodda R, Wu FI, Liu MS, Jen AKY. Macromolecules 2003;36:6698.

[11] Wu FI, Shih PI, Shu CF, Tung YL, Chi Y. Macromolecules 2005;38:9028.

[12] Pu YJ, Soma M, Kido J, Nishide H. Chem Mater 2001;13:3817.

[13] Liang FS, Pu YJ, Kurata T, Kido J, Nishide H. Polymer 2005;46:3767.

[14] Liang FS, Kurata T, Nishide H, Kido J. J Polym Sci Part A: Polym Chem 2005;43:5765.

[15] Miteva T, Meisel A, Knoll W, Nothofer HG, Scherf U, Muller DC, et al. Adv Mater 2001;13:565.

[16] Fu YQ, Li Y, Li J, Yan SK, Bo ZS. Macromolecules 2004;37:6395.

[17] Liou GS, Hsiao SH, Chen WC, Yen HJ. Macromolecules 2006;39:6036.

[18] Oishi Y, Mori K, Hirahara H, Fujimura Y, Miya K. Jpn Pat 11-255723, 1999.

[19] Liou GS, Hsiao SH, Huang HM, Chang CW, Yen HJ. J Polym Res 2007;14:191.

[20] Demas JN, Crosby GA. J Phys Chem 1971;75:991.

[21] Yang CP, Liou GS, Chen RS, Yang CY. J Polym Sci Part A: Polym Chem 2000;38:1090.

[22] Roman MM, Sancenon F. Chem Rev 2003;103:4419.

[23] Xue C, Chen Z, Wen Y, Luo FT, Chen J, Liu H. Langmuir 2005;21:7860.

[24] Feng L, Zhang C, Chen Z, Qin A, Yuan M, Bai F. J Appl Polym Sci 2006;100:923.

[25] He Q, Lin HZ, Wang YF, Zhang B, Wang ZM, Lei GT, et al. Adv Funct Mater 2006;16:1343.

[26] Katan C, Terenziani F, Mongin O, Werts MHV, Porre‘s L, Pons T et al. J Phys Chem A 2005;109:3024.

[27] Christian R. Chem Rev 1994;94:2319. 